\title{
Serum zinc level and dietary zinc intake status in non-alcoholic fatty liver disease: A meta-analysis and systematic review
}

\author{
Sevginur Akdas ${ }^{1}$, (1) Nuray Yazihan ${ }^{1,2}$ \\ ${ }^{1}$ Department of Interdisciplinary Food, Metabolism and Clinical Nutrition, Ankara University, Institute of Health Sciences, Ankara, Turkey; ${ }^{2}$ Department of \\ Internal Medicine, Division of Pathophysiology, Ankara University Faculty of Medicine, Ankara, Turkey
}

\begin{abstract}
Background and Aim: Non-alcoholic fatty liver disease (NAFLD) is a common health problem related to diet and a sedentary lifestyle. Zinc has essential roles in diabetes, insulin resistance and inflammation. This metaanalysis aims to evaluate the relationship between NAFLD and dietary zinc intake/serum zinc levels.

Materials and Methods: A systematic search was performed in PubMed, Web of Science, and Scopus databases for relevant English articles with mean/standard deviation values of serum zinc levels $(\mu \mathrm{g} / \mathrm{dL})$ and dietary zinc intake (mg/day) up to February 2020. We screened "fatty liver disease" and "zinc" keywords; totally 864 articles, eight of them were found to have suitable serum zinc level or daily zinc intake data for meta-analysis.

Results: Serum zinc level in NAFLD patients were lower than healthy controls (data from 984 individuals, FEM, $\mathrm{p}<0.00001$ ). The meta-analysis results of the nutritional zinc intake of totally 19438 individuals were similar in NAFLD and control groups (FEM, $\mathrm{p}=0.36$ ).

Conclusion: Serum zinc levels were lower in NAFLD patients, even though they have similar zinc intake in the diet, which suggests that there may be an absorption problem or increased need, with a distributional disorder which results in lower serum zinc levels. Further studies need to evaluate the role of zinc in NAFLD.
\end{abstract}

Keywords: Diet; liver; NAFLD; trace elements; zinc.

\section{Introduction}

Non-alcoholic fatty liver disease (NAFLD) is the most common cause of chronic liver disease in Western countries, which is estimated to be the most common indication for liver transplantation in the following 10 years. The clinical burden of NAFLD is not only limited to liver-related morbidity and mortality but also there is growing evidence that NAFLD is a multi-system disease affecting multi-system organs and regulatory pathways. Diabetes and insulin resistance pathways are the most common outcomes which NAFLD is related ${ }^{[1]}$ A recent study shows that the presence of NAFLD is a long-term health problem and often occurs with metabolic disorders. In this study, it is observed that the factors associated with the presence of significant liver fibrosis are diabetes

Received: April 08, 2020; Accepted: May 04, 2020; Available online: May 21, 2020 Corresponding author: Nuray Yazihan; Ankara Universitesi Tip Fakultesi, Dahiliye Anabilim Dali, Patofizyoloji Bilim Dali, Morfoloji Binasi, Sihhiye, Ankara, Turkey Phone: +90 31259580 56; e-mail: nurayyazihan@yahoo.com

(c) (i) (\$) OPEN ACCESS

cc) This work is licensed under a Creative Commons Attribution-NonCommercial 4.0 International License.

(C) Copyright 2020 by Hepatology Forum - Available online at www.hepatologyforum.org
$(\mathrm{OR}=4.8)$, obesity $(\mathrm{OR}=3.4)$, hypertension $(\mathrm{OR}=3.3)$ and insulin resistance $(\mathrm{OR}=2.0)$. In addition, the relationship between the presence of hyperlipidemia and NAFLD development was higher than other metabolic outcomes (53\% insulin resistance, $60 \%$ hyperlipidemia) ${ }^{[2]}$

In these processes, many macro and micronutrients are studied to find their relationship with chronic diseases and metabolic outcomes. Zinc is one of the most important trace elements and their metabolic effects are shown with different studies. Zinc has a direct link with insulin synthesis, storage, and secretion pathways, ${ }^{[3,4]}$ which may cause diabetes and insulin resistance that the two of the most related factors with NAFLD. Lower zinc intake is found to be associated with decreased insulin sensitivity and impaired glucose utilization, whereas adequate zinc intakes may be protective against T2DM..$^{[5,6]}$ The reason of focusing on the zinc role on metabolic diseases as NAFLD, obesity and metabolic syndrome might be summarized with several functions regulatory features of zinc, such as urea and ammonium metabolism in the liver, ${ }^{[7,8]}$ appetite regulation $^{[9]}$ and leptin production ${ }^{[10,11]}$ in addition to its key role on glucose metabolism that mentioned before.

This indicates that zinc, which also has key functions in diabetes and obesity pathogenesis, may have a role in the NAFLD. The purpose of this meta-analysis is to demonstrate the relationship between disease development and zinc by evaluating serum zinc levels and zinc uptake data in studies conducted in the presence of NAFLD.

\section{Materials and Methods}

\section{Eligibility Criteria}

All human studies, including serum zinc levels or daily dietary zinc intake of NAFLD patients with mean and standard deviation, were assessed to meta-analyze. There were no restrictions imposed on age, gender or on any other population characteristic, such as race or Body Mass Index.

The inclusion of the studies in the meta-analysis by the researchers was carried out with the following criteria: determining the serum zinc levels, including the mean and the standard deviation values, reporting the zinc values using $\mu \mathrm{g} / \mathrm{dL}$ or a suitable unit that can be converted to this unit, giving the sample size of the groups, making the diagnosis of the disease according to the criteria accepted in the literature, and indicating that appropriate conditions were met for the collection of samples.

\section{Sources and Search}

PRISMA procedures were followed for searching and evaluating the data. PubMed, Web of Science and Scopus databases were searched 


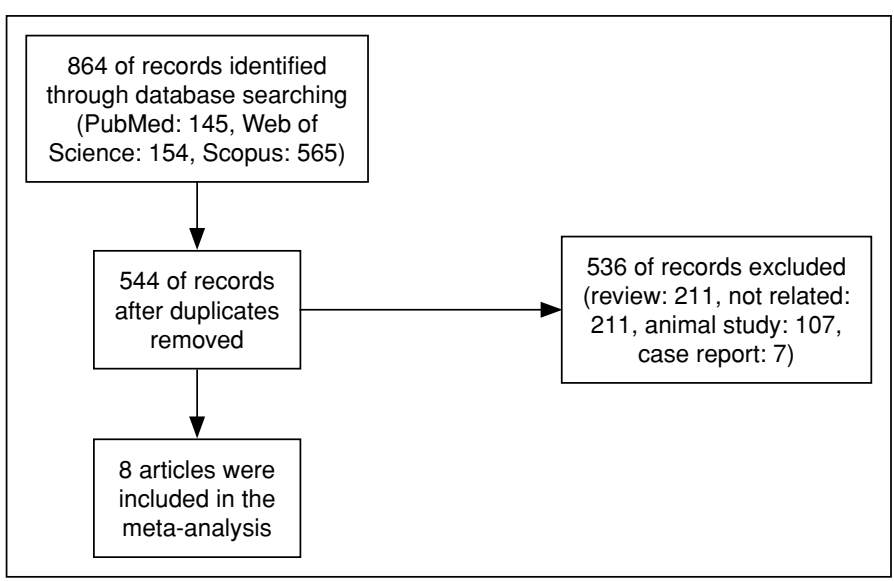

Figure 1. Flow diagram of the eligibility of the studies.

without any date restrictions and relevant articles were detected. Searching was being performed until February 2020. Searching keywords were "fatty liver disease" and "zinc" for all databases.

\section{Statistical Analysis}

Pooled data were calculated to assess the relation between serum zinc level/zinc intake and NAFLD. The I 2 was used for measuring heterogeneity as described before (I $\%$ values of $0-25,25-50,50-75$, and 75-100 represent no, low, moderate, and high heterogeneity). ${ }^{[12]}$ The fixed effect model was used to combine the results. Meta-analysis was performed with RevMan 5.3. (Cochrane Collaboration, Copenhagen, 2014). GraphPad Prism 6 was used for correlation analyses and figures.

\section{Risk of Bias Assessment of Studies}

The risk of bias for each study was assessed either as low, unclear, or high risk for each of the following criteria: selection bias, performance bias, detection bias, attrition bias, and reporting bias and other as described in the Cochrane Handbook. ${ }^{[13]}$

\section{Results}

As a result of PubMed, Scopus, and Web of Science search, totally 864 articles were screened. After the articles common in two or three data- bases were excluded, it was seen that 211 articles were review, 107 articles were animal study, seven articles were case reports and 211 articles were not related/did not include the inclusion criteria according to the information obtained from the titles, abstracts or full texts. A total of eight articles ${ }^{[14-21]}$ were found to be suitable for meta-analysis that four of them were used for evaluation of serum zinc status and four of them were used for evaluation of zinc intake relation with NAFLD (Fig. 1). Publishing dates of articles met the predefined inclusion criteria and were included in the meta-analysis ranged from 2007 to 2019. Characteristics of the studies are given in Table 1 .

In studies that include serum zinc level or zinc intake data of NAFLD patients were evaluated with the fixed effect model. The heterogeneity among the studies was found to be high both in serum zinc level $(88 \%)$ and zinc intake from diet (84\%) assessments. Serum zinc level in NAFLD patients was found to be significantly lower than healthy controls according to data obtained from 984 individuals (FEM, $\mathrm{p}<0.00001$, mean difference: -7.10 [-9.14,-5.06]) (Fig. 2). Total mean-sd values of serum zinc level according to weight of studies (depending on sample size) were $100.822-30.048 \mu \mathrm{g} / \mathrm{dL}$ for control group and 97.049-33.276 $\mu \mathrm{g} / \mathrm{dL}$ for NAFLD group. The meta-analysis results of the zinc intake status of totally 19438 individuals were showed that there was no significant difference between NAFLD and control groups (FEM, p:0.36, mean difference: -0.03 [-0.11,0.04]) (Fig. 3).

However, dietary zinc intake of NAFLD groups was found to be correlated with dietary carbohydrate intake (p: 0.0283 , R: 0.6866$)$ but not with dietary protein, fat and calorie intake status (Fig. 4). Total meanSD values of dietary zinc intake were $9.608-3.718 \mathrm{mg}$ /day for control group and $9.422-1.855 \mathrm{mg} /$ day for NAFLD group. When the difference between mean values of the dietary pattern of healthy and NAFLD groups obtained from different studies was analyzed, it was shown that NAFLD groups' dietary energy $(\mathrm{p}=0.0018)$, carbohydrate $(\mathrm{p}=0.0113)$, fat $(0.0063)$ were significantly higher than control groups' however protein $(\mathrm{p}=0.0833)$ and zinc $(\mathrm{p}=0.1292)$ content of diet did not show a significant difference (Fig. 5).

The funnel plots shown in Figure 6 do not suggest evidence of publication bias in the studies included in this meta-analysis.

\section{Discussion}

With this meta-analysis, it was observed that serum zinc levels were lower in patients with NAFLD compared to healthy individuals. How-

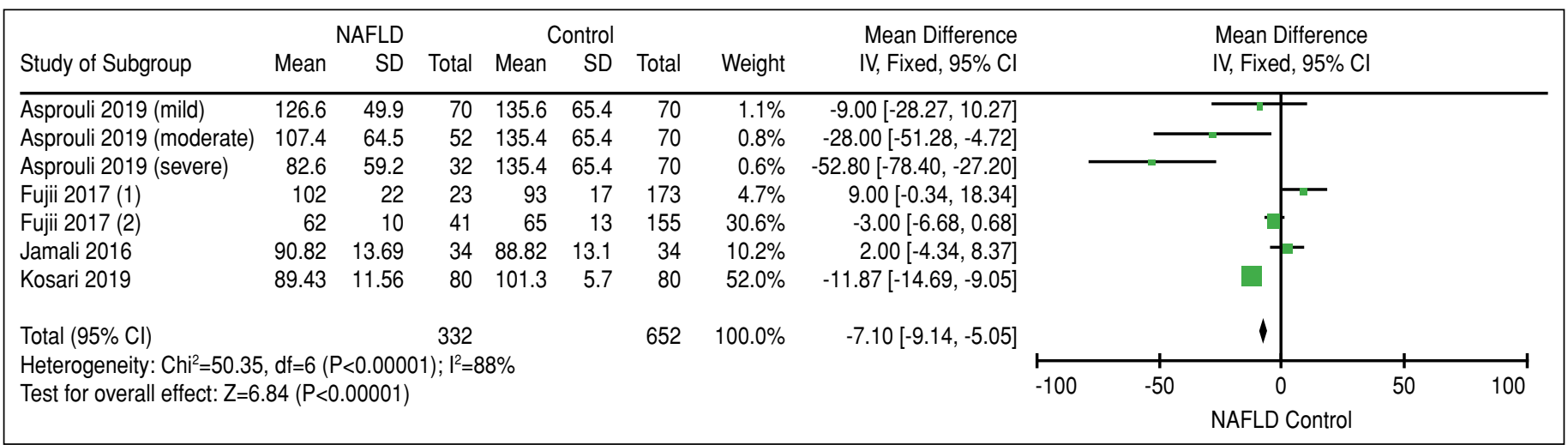

Figure 2. The fixed effect model of serum zinc level status (mild, moderate, severe: NAFLD status of patients; (1): Patients whose data obtained in $1^{\text {st }}$ month after pancreatoduodenectomy: ${ }^{[39]}$ Patients whose data obtained in $6^{\text {th }}$ month after pancreatoduodenectomy).

NAFDL: Non-alcoholic fatty liver disease. 


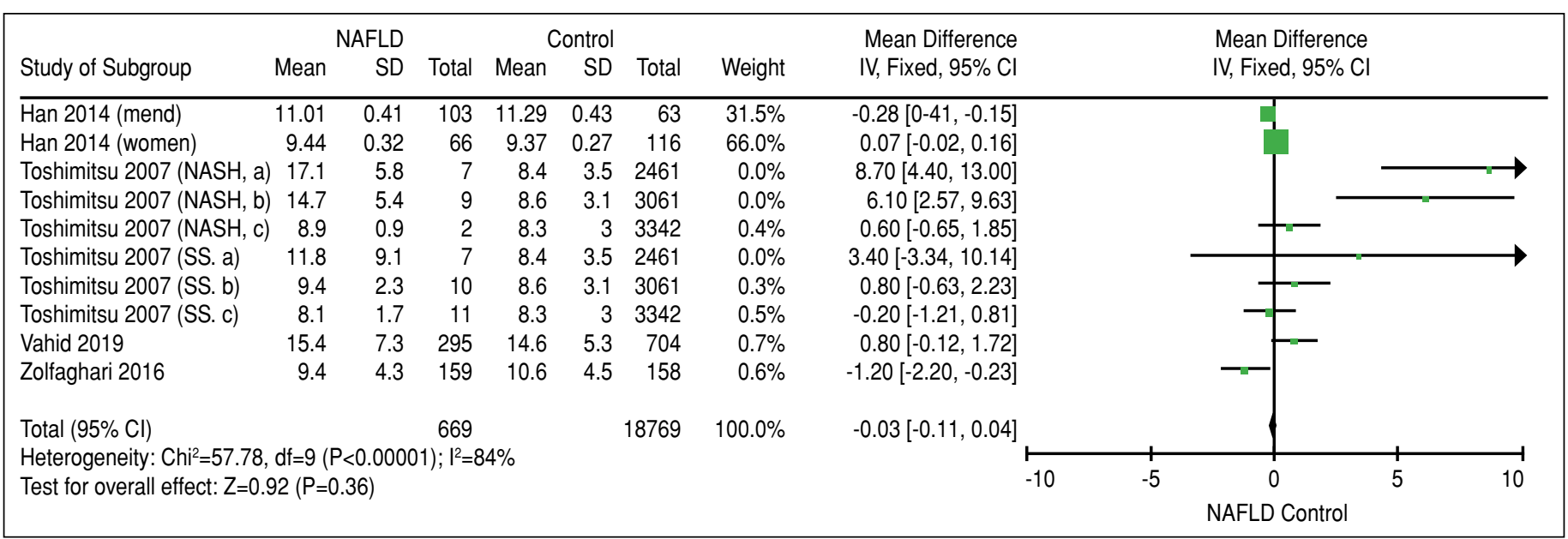

Figure 3. The fixed effect model of dietary zinc intake status (SS: Simple Steatosis, NASH: Non-alcoholic Steatohepatitis, a: 20-39 ages, b: 40-59 ages, c: $60+$ ages).

NAFDL: Non-alcoholic fatty liver disease.

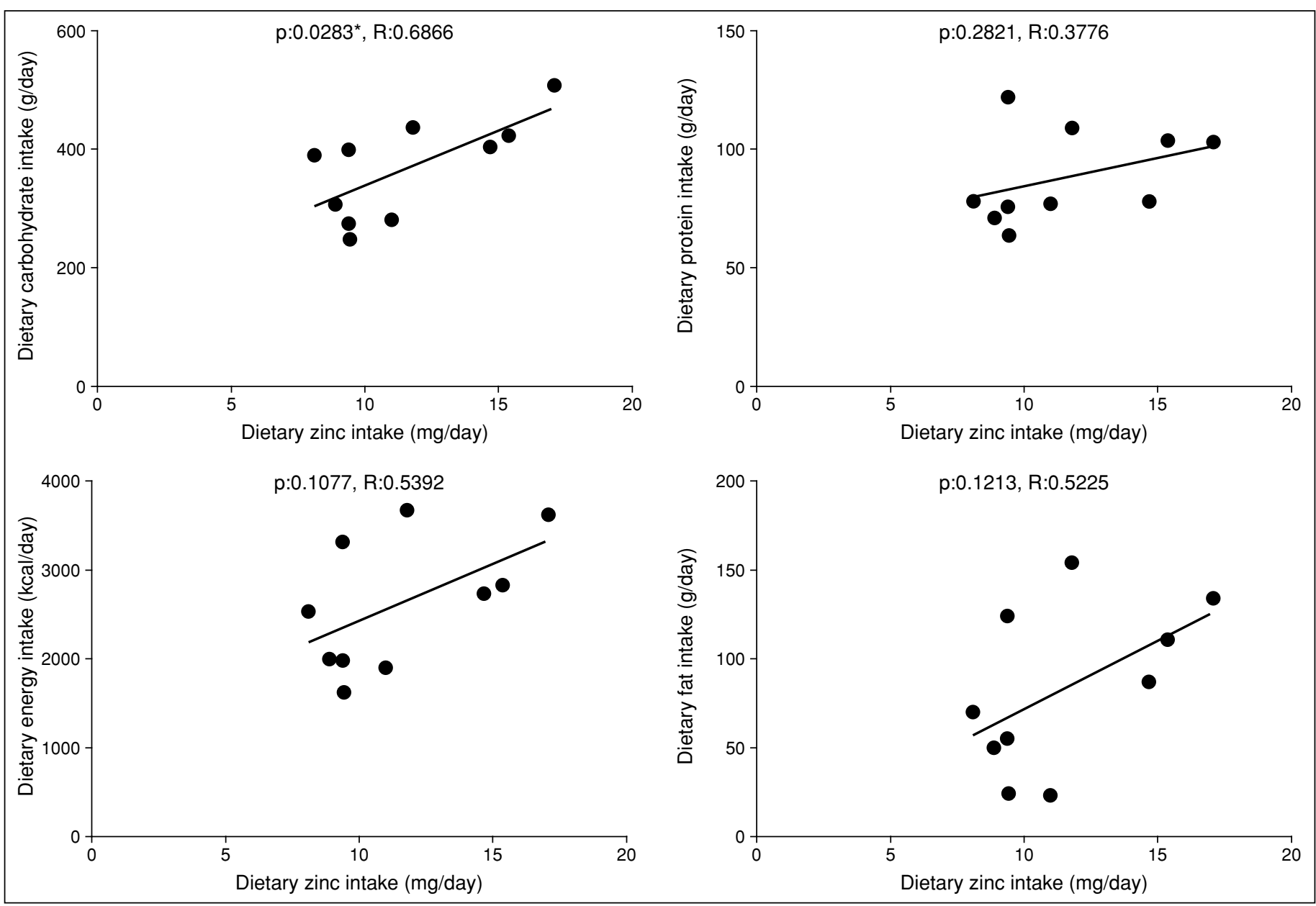

Figure 4. Correlation analysis of relationship between dietary pattern and zinc intake of non-alcoholic fatty liver disease groups.

ever, the dietary zinc intake status did not show a difference between groups. Thus, it might be thought that although patients with NAFLD intake adequate zinc with diet, there might be an absorption problem or increased using, storage, distributional dysfunction or excretion of zinc because it was shown that serum zinc levels were lower than control.

In the study of Ito et al., ${ }^{[22]}$ serum zinc level was found to be decreased with the progression of hepatic fibrosis. There was not a correlation with inflammatory grades; however, zinc levels were significantly cor- 

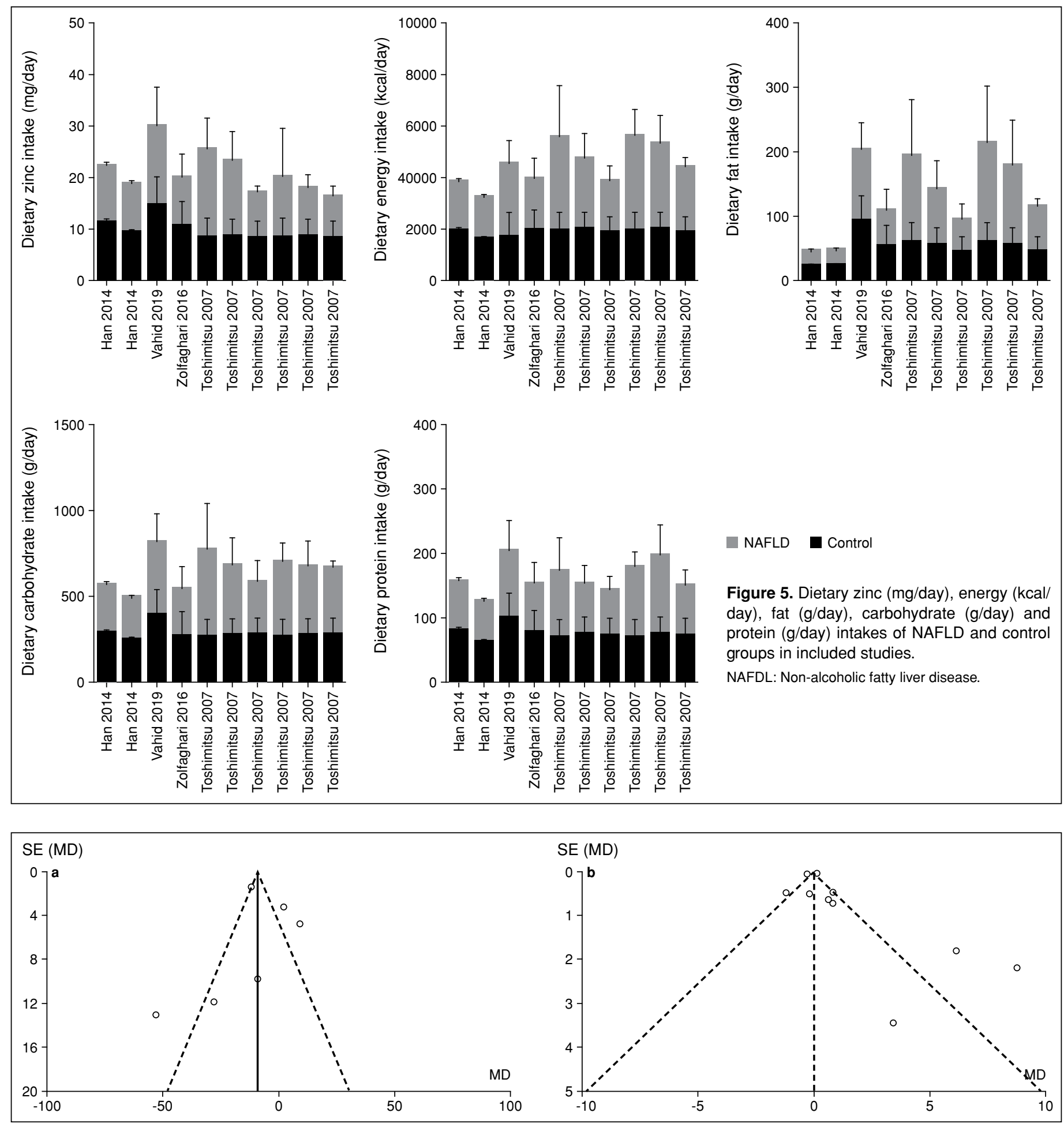

Figure 6. (a) Funnel plot of studies included in the meta-analysis of serum zinc level. (b) Funnel plot of the studies included in the meta-analysis of the dietary zinc intake.

related with NAFLD fibrosis score in biopsy-proven NAFLD patients. Also, in the following study of the same study group, it was stated that serum zinc levels were useful for predicting hepatic and extrahepatic malignancies in NAFLD. ${ }^{[23]}$ Similarly, in another NAFLD study, it was observed that serum zinc level had reverse and strong correlation with liver stiffness, which increased with aging. ${ }^{[24]}$

It is stated that zinc absorption is influenced by dietary zinc intake, not serum zinc status. As dietary zinc increases, the total amount of zinc absorbed increases, while the percentage absorbed decreases. The gastrointestinal tract adjusts endogenous zinc losses to the amount ab- 


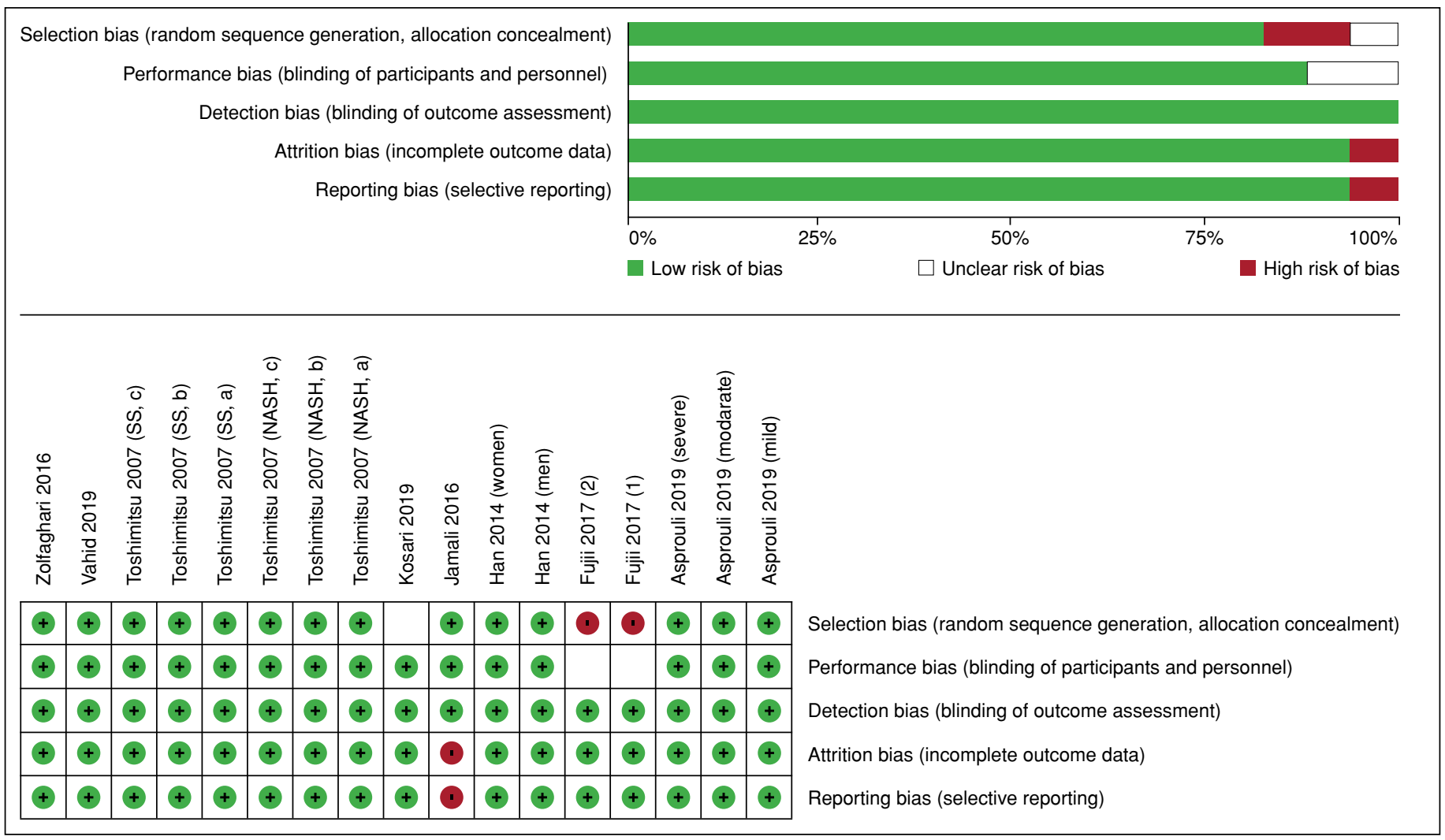

Figure 7. Risk of the bias summary and graph of the risk of the bias items for each included study.

sorbed, protecting the whole body zinc homeostasis. ${ }^{[25,26]}$ The good dietary zinc sources are known as oysters, red meat, beans, nuts, whole grains and dairy products. Generally, protein sources, such as meat, are known as zinc source. However, carbohydrate does not mean sugar and also there are carbohydrate sources, such as whole grains, beans, legumes also contain zinc that there was a correlation between carbohydrate and zinc intake in NAFLD patients in our results. It should be considered that phytates which are present in plant-based foods inhibit zinc absorption. Although patients get enough zinc from plant-based diet, the absorption of zinc could be limited, ${ }^{[27,28]}$ and it can be thought according to our results, dietary zinc intake of the patients with NAFLD might be based on carbohydrate intake which might decrease the absorption. It can explain why NAFLD patients have lower serum zinc level, while they have similar dietary zinc intake status with control subjects.

In the study of Ho et al., ${ }^{[29]}$ zinc bioavailability, serum zinc status and zinc intake were investigated in obese adolescents in two groups. It was shown that adolescents in the high-carbohydrate diet group had higher dietary phytate intake than in moderate carbohydrate-increased protein group, which also increased the phytate/zinc molar ratio significantly. Plasma zinc level was found to be positively correlated with dietary zinc intake, dietary zinc $(\mathrm{mg} / \mathrm{KJ})$ and protein $(\mathrm{E} \%)$ density. It was shown a negative correlation with dietary carbohydrate $(\mathrm{E} \%){ }^{[29]} \mathrm{In}$ addition, articles related to zinc sources and bioavailability are limited in the literature. There is a need for new studies and meta-analyses related to the absorption of zinc from foods.

In a previous study, it was mentioned that high fat, high cholesterol and high fructose diet might cause degeneration and $15-30 \%$ enteric neuron loss, which also resulted in damage to remaining neurons. Enteric neu- ronal loss was found to be related to NASH, fibrosis. ${ }^{[30]}$ Also, reduced gut motility by neuronal loss is thought to contribute to the dysbiosis of microbiota and progression of steatohepatitis, while it causes decreased nutrient mix in the intestine and adequate and appropriate absorption. ${ }^{[31]}$ Furthermore, during zinc homeostasis, it is important that secretion of zinc from special tissues, which include a high level of zinc to maintain the serum zinc at an optimum level. Zinc-DMT1/FPN1 axis is important for zinc excretion and crosstalk via modulating the iron metabolism. DMT1 and FPN1 take part in the control of iron and zinc levels. Anemic patients have a higher risk of zinc deficiency and most of them have nutritional deficiencies and high phytate diet. Exocrine pancreas, liver, intestine have a very high rate of zinc turnover. About $30-40 \%$ of zinc in portal blood is exchanged with the liver. ${ }^{[28,32]}$ This exchange may have degenerated with disease progression and it can be the reason for lower serum zinc level in NAFLD patients. As mentioned before, zinc is essential for pancreas tissue to secretion and storage of insulin in granules. ${ }^{[3,4]}$ It may be thought that in insulin resistance-related diseases, zinc need in the pancreas is increased for the production of insulin. Also, the exocrine pancreas needs zinc for secretion function. It is mentioned that $1-2 \mathrm{mg}$ /day of zinc is coming from exocrine pancreas to intestine with the normal dietary intakes of nutrients, which can also called as zinc homeostasis in intestinal-pancreatic axis. ${ }^{[32,33]}$ However, in our previous study, we found that liver tissue zinc levels of rats in the MetS group were also shown to be significantly reduced compared to the control group, in addition to serum and pancreatic tissue zinc level. Also, we found that there was importantly increased zinc storage in heart and kidney tissues, which shows a distributional dysfunction. ${ }^{[34]}$ These results suggest that zinc levels have an important role in the liver in diseases, such as fatty liver, obesity-MetS, which are thought to have 


\begin{tabular}{|c|c|c|c|c|c|c|}
\hline \multirow[t]{2}{*}{ Asprouli $\left[{ }^{[18]} 2019\right.$} & $\begin{array}{l}\text { Diagnosis criteria: American Association for } \\
\text { the Study of Liver Diseases (AASLD) guideline } \\
\text { Separation reason for case group: Disease status } \\
\text { (Mild non-alcoholic fatty liver disease [NAFLD]). } \\
\text { Serum zinc level determination: ICP-MS }\end{array}$ & $\begin{array}{l}\text { Serum zinc } \\
\text { level } \mu \mathrm{g} / \mathrm{dL}\end{array}$ & $135.4-65.4$ & 70 & $126.6-49.9$ & 35 \\
\hline & $\begin{array}{l}\text { Diagnosis criteria: AASLD guideline } \\
\text { Separation reason for case group: Disease status } \\
\text { (Moderate NAFLD). } \\
\text { Serum zinc level determination: ICP-MS }\end{array}$ & $\begin{array}{l}\text { Serum zinc } \\
\text { level } \mu \mathrm{g} / \mathrm{dL}\end{array}$ & $135.4-65.4$ & 70 & $107.4-64.5$ & 52 \\
\hline \multirow[t]{2}{*}{ Fujii ${ }^{[15]} 2017$} & $\begin{array}{l}\text { Diagnosis criteria: Computed Tomography } \\
\text { Separation reason for case group: Duration after } \\
\text { pancreatoduodenectomy ( } 1^{\text {st }} \text { month after the } \\
\text { operation). } \\
\text { Serum zinc level determination: Not specified }\end{array}$ & $\begin{array}{l}\text { Serum zinc } \\
\text { level } \mu \mathrm{g} / \mathrm{dL}\end{array}$ & $93-17$ & 173 & $102-22$ & 23 \\
\hline & $\begin{array}{l}\text { Diagnosis criteria: Computed Tomography } \\
\text { Separation reason for case group: Duration after } \\
\text { pancreatoduodenectomy ( } 6^{\text {th }} \text { month after the } \\
\text { operation). } \\
\text { Serum zinc level determination: Not specified }\end{array}$ & $\begin{array}{l}\text { Serum zinc } \\
\text { level } \mu \mathrm{g} / \mathrm{dL}\end{array}$ & $65-13$ & 155 & $62-10$ & 41 \\
\hline & $\begin{array}{l}\text { Diagnosis criteria: (i) patients were diagnosed with } \\
\text { fatty liver through } \\
\text { abdominal ultrasound examination in the past three } \\
\text { months and,15] } \\
\text { the consumption of alcohol in a } 1 \text {-week period was } \\
140 \mathrm{~g} \text { or less } \\
\text { for men and } 70 \mathrm{~g} \text { or less for women } \\
\text { Separation reason: Depending on gender (Women) } \\
\text { Dietary zinc status determination: Food record } \\
\text { method for four or five days, or } 24 \text {-hour dietary recall }\end{array}$ & $\begin{array}{l}\text { Dietary zinc } \\
\text { intake } \mathrm{mg} / \text { day }\end{array}$ & $9.37-0.27$ & 116 & $9.44-0.32$ & 66 \\
\hline Jamali ${ }^{[14]} 2016$ & $\begin{array}{l}\text { Diagnosis criteria: Lab tests and liver biopsy } \\
\text { Serum zinc level determination: Atomic Absorption } \\
\text { Spectroscopy }\end{array}$ & $\begin{array}{l}\text { Serum zinc } \\
\text { level } \mu \mathrm{g} / \mathrm{dL}\end{array}$ & $88.82-13.10$ & 34 & $90.82-13.69$ & 54 \\
\hline Kosari[21] 2019 & $\begin{array}{l}\text { Diagnosis criteria: Liver biopsy } \\
\text { Serum zinc level determination: Not specified }\end{array}$ & $\begin{array}{l}\text { Serum zinc } \\
\text { level } \mu \mathrm{g} / \mathrm{dL}\end{array}$ & $101.3-5.7$ & 80 & $89.43-11.56$ & 80 \\
\hline Toshimitsu ${ }^{[19]} 2007$ & $\begin{array}{l}\text { Diagnosis criteria: Histologic findings } \\
\text { Separation reason: Depending on disease status and }\end{array}$ & $\begin{array}{l}\text { Dietary zinc } \\
\text { intake } \mathrm{mg} / \mathrm{day}\end{array}$ & $8.4-3.5$ & 2461 & $17.1-5.8$ & 7 \\
\hline
\end{tabular}




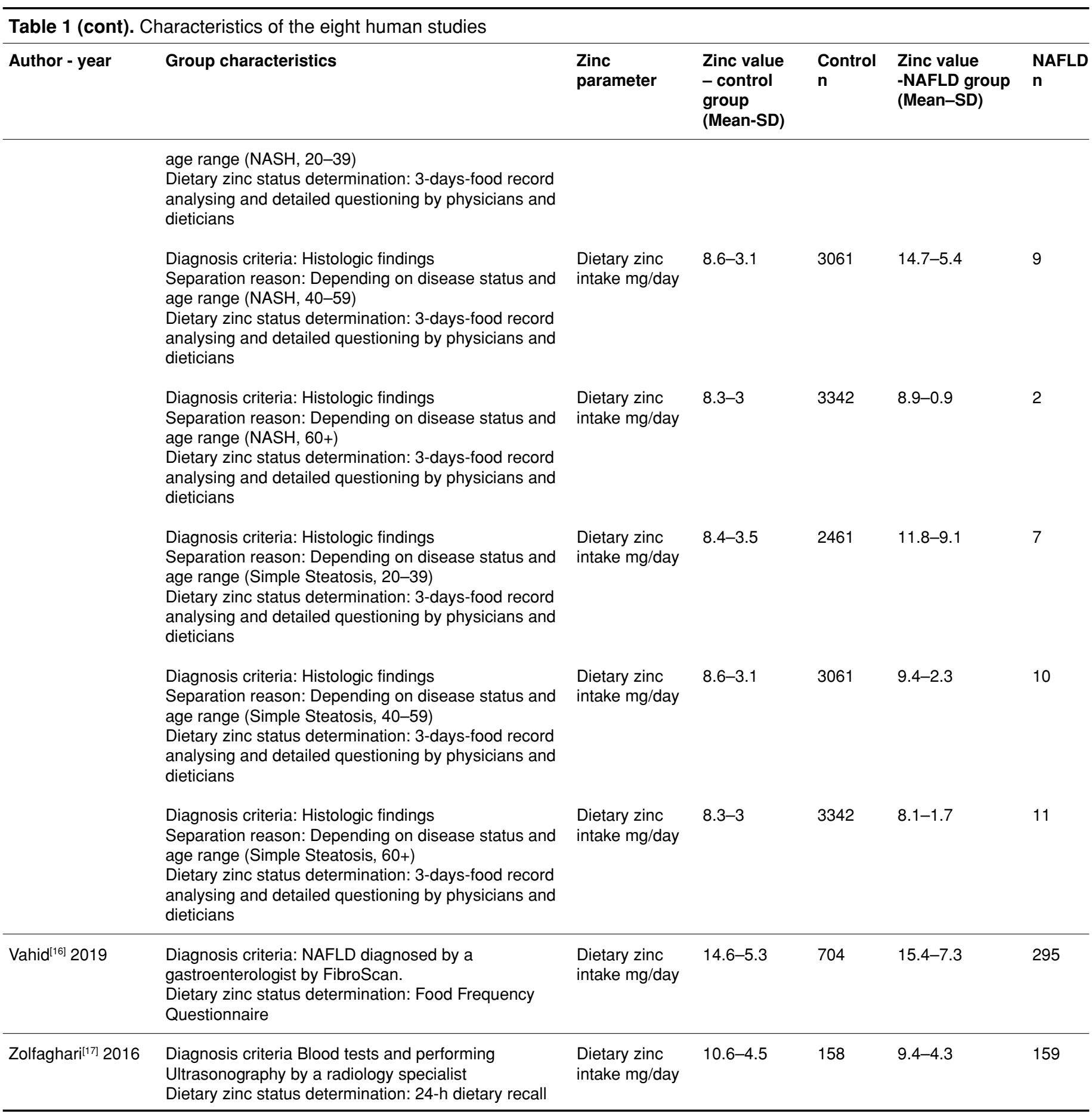

similar pathogenesis. In the literature, it has been reported that the entry of serum zinc to the intracellular area is stimulated in low-level inflammation. ${ }^{[35,36]}$ This was shown with increased erythrocyte zinc levels and increased urinary zinc excretion in a human study that investigate MetS and zinc relation. ${ }^{[37]}$ In the obesity-induced NAFLD model, both serum and liver zinc levels were significantly lower than the control. ${ }^{[38]}$ According to our findings and literature data, it should be expressed that serum zinc level may be a good indicator of disease progression and/ or have an important function on pathogenesis; however, to understand both the mechanism underlying the serum zinc level role on NAFLD and dietary zinc intake and NAFLD relation, further studies are needed. We accept the limits of our work based on the quality of the studies and data in the literature. Some of the limitations of our current meta-analysis are due to the determination of zinc levels in serum and diet, disease or patients' conditions and heterogeneity. The statistical heterogeneity of the data was high. However, clinical heterogeneity can be observed and is a natural result for meta-analysis and should be considered when interpreting the results of this study. It was performed by evaluating the 
PRISMA checklist. On the other hand, to our knowledge, this study is the first meta-analysis in the literature evaluating the relationship between serum zinc levels, dietary zinc intake and NAFLD.

\section{Conclusion}

In conclusion, as a result of the meta-analysis, it was found that serum zinc levels could have an important role in the pathogenesis of NAFLD. Also, it was seen that dietary zinc intake, especially from plant sources similar in NAFLD and healthy individuals. To our knowledge, this paper is the first meta-analysis on the relationships between both the serum\&dietary zinc status with NAFLD. For further understanding of the underlying mechanism, different clinical and animal model studies are needed to enlighten zinc homeostasis at the liver and systemically level in NAFLD conditions. Also, the dietary pattern which NAFLD patients have and intestinal changes should be investigated to understand whether decreased serum zinc level depended on decreased zinc absorption or increased zinc need in the body to regulate disease outcomes such as insulin secretion, inflammation or decreased liver functions.

\section{Peer-review: Externally peer-reviewed.}

Author Contributions: SA: Data collection/processing, literature review, design, analyses, writer; NY: Design, supervision, analyses, literature review, writer, critical review.

Conflict of Interest: The authors have no conflict of interest to declare.

Financial Disclosure: The authors declared that this study has received no financial support.

\section{References}

1. Byrne CD, Targher G. NAFLD: a multisystem disease. J Hepatol 2015;62(1 Suppl):S47-64.

2. Seval GC, Kabacam G, Yakut M, Seven G, Savas B, Elhan A, et al. The natural course of non-alcoholic fatty liver disease. Hepatology Forum 2020;1(1):20-24.

3. Figlewicz DP, Forhan SE, Hodgson AT, Grodsky GM. 65Zinc and endogenous zinc content and distribution in islets in relationship to insulin content. Endocrinology 1984;115(3):877-881.

4. Søndergaard LG, Stoltenberg M, Doering P, Flyvbjerg A, Rungby J. Zinc ions in the endocrine and exocrine pancreas of zinc deficient rats. Histol Histopathol 2006;21(6):619-625.

5. Vashum KP, McEvoy M, Shi Z, Milton AH, Islam MR, Sibbritt D,. Is dietary zinc protective for type 2 diabetes? Results from the Australian longitudinal study on women's health. BMC Endocr Disord 2013;13:40.

6. Sun Q, van Dam RM, Willett WC, Hu FB. Prospective study of zinc intake and risk of type 2 diabetes in women. Diabetes Care 2009;32(4):629-634.

7. Chavez-Tapia NC, Cesar-Arce A, Barrientos-Gutiérrez T, Villegas-López FA, Méndez-Sanchez N, Uribe M. A systematic review and meta-analysis of the use of oral zinc in the treatment of hepatic encephalopathy. Nutr J 2013;12:74

8. Marchesini G, Fabbri A, Bianchi G, Brizi M, Zoli M. Zinc supplementation and amino acid-nitrogen metabolism in patients with advanced cirrhosis. Hepatology 1996;23(5):1084-1092.

9. McClain C, Stuart M, Kasarskis E, Humphries L. Zinc, appetite regulation and eating disorders. Prog Clin Biol Res 1993;380:47-64.

10. Chen MD, Lin PY. Zinc-induced hyperleptinemia relates to the amelioration of sucrose-induced obesity with zinc repletion. Obes Res 2000;8(7):525-529.

11. Chen MD, Song YM, Lin PY. Zinc may be a mediator of leptin production in humans. Life Sci 2000;66(22):2143-2149.
12. Higgins JP, Thompson SG, Deeks JJ, Altman DG. Measuring inconsistency in meta-analyses. BMJ 2003;327(7414):557-560.

13. Higgins J, Green S. Cochrane handbook for systematic reviews of interventions version. The Cochrane Collaboration; 2011.

14. Jamali R, Abad EMJ, Ramim T. Serum Zinc level and liver pathological grading correlation in nonalcoholic steatohepatitis, in a university hospital in Tehran. Tehran University Medical Journal 2016;74(5):330-336.

15. Fujii Y, Nanashima A, Hiyoshi M, Imamura N, Yano K, Hamada T. Risk factors for development of nonalcoholic fatty liver disease after pancreatoduodenectomy. Ann Gastroenterol Surg 2017;1(3):226-231.

16. Vahid F, Hekmatdoost A, Mirmajidi S, Doaei S, Rahmani D, Faghfoori Z. Association Between Index of Nutritional Quality and Nonalcoholic Fatty Liver Disease: The Role of Vitamin D and B Group. Am J Med Sci 2019;358(3):212-218.

17. Zolfaghari H, Askari G, Siassi F, Feizi A, Sotoudeh G. Intake of Nutrients, Fiber, and Sugar in Patients with Nonalcoholic Fatty Liver Disease in Comparison to Healthy Individuals. Int J Prev Med 2016;7:98.

18. Asprouli E, Kalafati IP, Sakellari A, Karavoltsos S, Vlachogiannakos J, Revenas $\mathrm{K}$, et al. Evaluation of plasma trace elements in different stages of nonalcoholic fatty liver disease. Biological Trace Element Research 2019;188(2):326-333.

19. Toshimitsu K, Matsuura B, Ohkubo I, Niiya T, Furukawa S, Hiasa Y, et al. Dietary habits and nutrient intake in non-alcoholic steatohepatitis. Nutrition 2007;23(1):46-52.

20. Han JM, Jo AN, Lee SM, Bae HS, Jun DW, Cho YK, et al. Associations between intakes of individual nutrients or whole food groups and non-alcoholic fatty liver disease among Korean adults. J Gastroenterol Hepatol 2014;29(6):1265-1272.

21. Kosari F, Jamali R, Ramim T, Mosavi Jahan Abad E. The Correlation between Serum Zinc Level and Liver Histology in Non-Alcoholic Steatohepatitis. Iran J Pathol 2019;14(1):17-25.

22. Ito $T$, Ishigami M, Ishizu $Y$, Kuzuya $T$, Honda $T$, Ishikawa $T$, et al. Correlation of serum zinc levels with pathological and laboratory findings in patients with nonalcoholic fatty liver disease. Eur J Gastroenterol Hepatol 2020;32(6):748-753.

23. Ito T, Ishigami M, Ishizu $\mathrm{Y}$, Kuzuya $\mathrm{T}$, Honda $\mathrm{T}$, Ishikawa $\mathrm{T}$, et al, Serum Nutritional Markers as Prognostic Factors for Hepatic and Extrahepatic Carcinogenesis in Japanese Patients with Nonalcoholic Fatty Liver Disease. Nutrition and Cancer 2019;72:1-8.

24. Hajiani E, Parsi A, Erfanian Taghvaei K, Morvaridi M. The Relationship between Serum Zinc Level and Liver Elastrography Using Fibroscan in Non-Alcoholic Fatty Liver Patients. Journal of Babol University of Medical Sciences 2018;20(3):29-35.

25. King JC. Does zinc absorption reflect zinc status? Int J Vitam Nutr Res 2010;80(4-5):300-306.

26. Hambidge KM, Miller LV, Westcott JE, Sheng X, Krebs NF. Zinc bioavailability and homeostasis. Am J Clin Nutr 2010;91(5):1478S-1483S.

27. The National Institutes of Health Office of Dietary Supplements. Zinc-Fact sheet for health professionals. Available at: https://ods.od.nih.gov/factsheets/Zinc-HealthProfessional/.

28. Gibson RS. Principles of Nutritional Assessment. USA: Oxford university press; 2005.

29. Ho M, Heath AM, Gow M, Baur LA, Cowell CT, Samman S, et al. Zinc Intake, Zinc Bioavailability and Plasma Zinc in Obese Adolescents with Clinical Insulin Resistance Following Low Energy Diets. Ann Nutr Metab 2016;69(2):135-141.

30. Rivera LR, Leung C, Pustovit RV, Hunne BL, Andrikopoulos S, Herath C, et al. Damage to enteric neurons occurs in mice that develop fatty liver disease but not diabetes in response to a high-fat diet. Neurogastroenterol Motil 2014;26(8):1188-1199.

31. Leung C, Rivera L, Furness JB, Angus PW. The role of the gut microbiota in NAFLD. Nat Rev Gastroenterol Hepatol 2016;13(7):412-425. 
32. Kondaiah P, Yaduvanshi PS, Sharp PA, Pullakhandam R. Iron and Zinc Homeostasis and Interactions: Does Enteric Zinc Excretion Cross-Talk with Intestinal Iron Absorption? Nutrients 2019;11(8):1885.

33. Liuzzi JP, Bobo JA, Lichten LA, Samuelson DA, Cousins RJ. Responsive transporter genes within the murine intestinal-pancreatic axis form a basis of zinc homeostasis. Proceedings of the National Academy of Sciences 2004;101(40):14355-14360.

34. Akdas S, Turan B, Durak A, Ayral PA, Yazihan N. The relationship between metabolic syndrome development and tissue trace elements status and inflammatory markers. Biological Trace Element Research 2020;1-9.

35. Gammoh NZ, Rink L. Zinc in Infection and Inflammation. Nutrients 2017;9(6):624
36. Foster M, Samman S. Zinc and regulation of inflammatory cytokines: implications for cardiometabolic disease. Nutrients 2012;4(7):676-694.

37. Freitas EP, Cunha AT, Aquino SL, Pedrosa LF, Lima SC, Lima JG, et al. Zinc Status Biomarkers and Cardiometabolic Risk Factors in Metabolic Syndrome: A Case Control Study. Nutrients 2017;9(2):175.

38. Gatiatulina ER, Popova EV, Polyakova VS, Skalnaya AA, Agletdinov EF, Nikonorov AA, et al. Evaluation of tissue metal and trace element content in a rat model of non-alcoholic fatty liver disease using ICP-DRC-MS. J Trace Elem Med Biol 2017;39:91-99.

39. Sun LL, Li BL, Xie HL, Fan F, Yu WZ, Wu BH, et al. Associations between the dietary intake of antioxidant nutrients and the risk of hip fracture in elderly Chinese: a case-control study. Br J Nutr 2014;112(10):1706-1714. 